BNL 51412

UCC-28

BNL --51412

(Particle Accelerators and

DE'2 006843

High-Voltage Mac:sines - TIC-4500)

ISA $81-3$

\title{
STABILITY OF SUPERCONDUCTING ISABELLE DIPOLE MAGNETS*
}

\author{
Stefan L. Wipf†
}

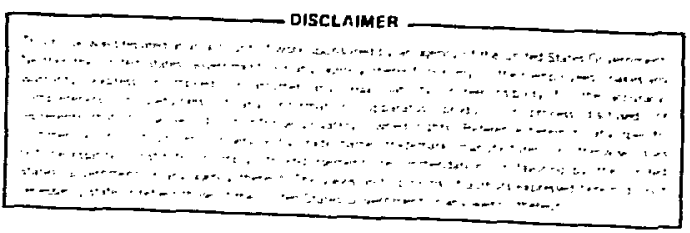

\section{April 1981}

*Report based on talk given at BNL on January 22. 1580

†Visitor From Los Alanos Scientilic Laboratory

\section{ACCELERATOR DEPARTMENT}

BROOKHAVEN NATIONAL LABORATORY

ASSOCIATED UNIVERSITIES, INC.

UPTON, NEW YORK 11973

UNDER CONTRACT NO DE-AC02-76CH100016 WITH THE

UNITED STATES DEPARTMENT OF ENERGY 
TABLE OF CONTENTS

\section{INTRODUCTION}

i. The ISABELLE Dipoles Are High Current Density Magnets

ii. Informative Estimates of Stability Can Be Made

II. MINIMUM PROPAGATING ZONES FOR ISABELLE MAGNETS ARE VERY S!

i. What Is an MPZ?

ii. The Simplest Geometry Is Spherical

iii. Stability Parameter

iv. Results for ISABELLE Coil Data

v. Adjustments for Nonisotropic Thermal Conduction

vi. An Equally Suitable Geometry Is the "Transmission Line Case"

vii. Comparison Between Spherical and Transmission Line Geometry

III. ABOUT DISTURBANCES

i. Energy Needed To Create the MPZ

ii. What Kind of Disturbance Will Cause a Quench?

iii. Comparison With ISABELLE Dipole Performance

IV. SHAT ELSE IS THERE TO SAY ABOUT STABILITY?

i. Could Some Improvement Be Gained by Changing the Cu:SC Ratio?

ii. Could Flux Jumps Be of Importance?

iii. Lyapunov Functions - Stability Represented by Means of a Generalized Potential Trough

V. GUESSING THE LIRITATIONS OF THE ISABELLE DIPOLE PERFORMANCE

i. Possible Disturbances in the ISABELLE Coils

ii. Most Likely Dominant Disturbance in ISABELLE Dipoles: Azimuthal Stick-S1ip Movement

iii. Longitudinal Extent of Stick-Slip Process

iv. Effect of Field Distribution

VI. RECOFMENDATIONS AIMED AT IMPROVING ISABELLE DIPOLE PERFORMANCE

i. What Information Might Be Usefu1

ii. Ways To Improve Stability

VII. CONCLUSIONS 


\section{ABSTRACT}

The concept of the minimum propagating zone (MPZ) is used to examined the causes of quenches in ISABELLE cosine theta superconducting dipole magnets. The size of disturbances large enough to exceed the MPZ and initiate quenches is estimated and compared with the size of disturbances which may be produced in the magnets. A suggestion for reducing the size of these disturbances through individual support of the coil block is outlined. 


\section{INTRODUCTION}

\section{i. The ISABELLE Dipoles Are High Current Density Magnets}

The design current density in the windings of the ISABELLE dipoles is $34 \mathrm{kA} / \mathrm{cm}^{2}$. The current density in a magnet designed without particular space 1 imitations rarely exceeds 5 to $10 \mathrm{kA} / \mathrm{cm}^{2}$. The pewer production at $10 \mathrm{kA} / \mathrm{cm}^{2}$, and with the superconductor above its critical temperature, approximates $2 \mathrm{~W} / \mathrm{cm}^{3}$. High current density magnets can operate in the superconducting mode as long as normal resistive zones, if they exist, do not exceed the size of a minimum propágating zone (MPZ). Any energy release in or near the winding is apt to create resistive zones by locally exceeding the critical temperature. The stability of a coil can be estimated by comparing the possible energy releases (disturbances) during operation with the MPZ size. With increasing current the MPZ decreases while the energy releases tend to increase. The crossover point establishes the quench region.

\section{ii. Informative Estundtes of Stability Can Be Made}

The general procedures used in this report are described in Ref. 1 . (Most illustrations used here are taken from Ref. 1 and are identified with their original figure number.) By sppro:imating the geometry of the ISABELLE winding with very simple one-dimensional gecmetries, existing ca1culated results can be used. The expected absolute accuracy may be little better than order of magnitude, but the information obtained, especially with regard to relative changes due to altering operational variables, is nevertheless very useful. Usvally such an approach is amply justified by the absence of reliable information on the parameters that are required for accurate computer calculations. Furthermore, the knowledge of size and location of actual disturbances is highly speculative; accurate calculations of MPZs are only useful in conjunction with similarly accurate data on disturbances.

The temperature of the coolant is an operating variable of interest. Comparative results for 4.5 and $3.8 \mathrm{~K}$ will be given.

II. MINIMUM PROPAGATING ZONES TOTK THE ISABELLE MAGNETS ARE VERY SMALL

i. What Is an MPZ?

The MPZ is a normal zone in which the Joule heating exactly balances the heat loss by conduction and coslant action. Normal zones larger than MPZ grow due to the surplus in Joule heating; conversely, smaller zones decay. A smaller normal zone $c_{c}$ ، be in thermal equilibrium with its

i. S.L. Wipf, "Stability and Degradation of Superconducting CurrentCarrying Devices", Los Alamos Scientific Lab Report LA-7275, Dec. 1978 (unpublished). 
surroundings if, in addition to the Joule heating, a localized heat input at its center is provided ("extra heating," see Figures B and G).

\section{ii. The Simplest Geometry Is Spherical}

Assume a winding that is infinite in all directions, with a current density $j$, an isotropic thermal conductivity $k$, and a temperature $T_{0}$ at infinity (Figure A). It is further assumed that the resistivity is $\rho$ for $T>T_{j}$ and that zero for $T<T_{j}$ is the critical temperature at current density $j$. (See Ref. $1 \mathrm{Ch} . \mathrm{V}$, pp. 8-12, Figures 6-8.) Figure A illustrates the spherical geometry.

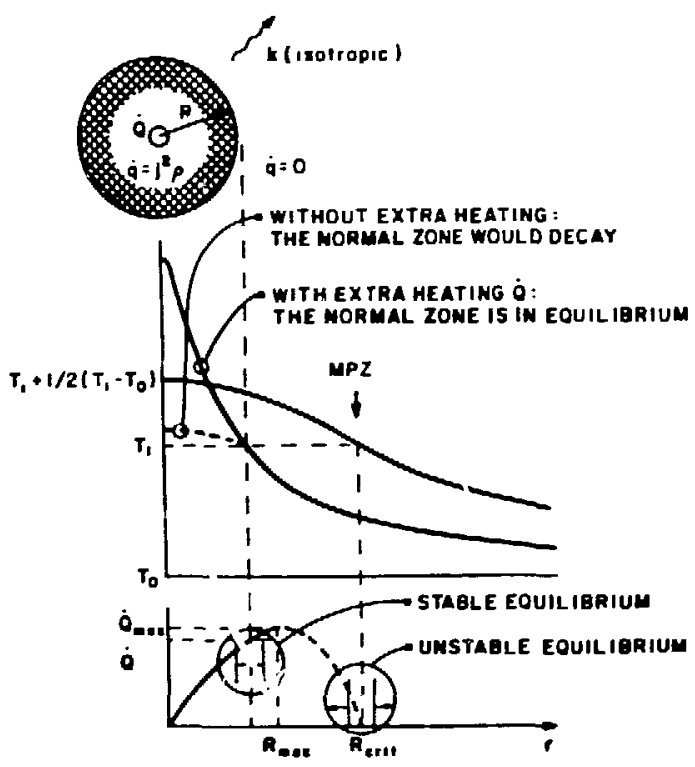

Figure A Spherical case. Top, normal zone $r<R$; middle, temperature inside and autside normal zone and temperature distribution for MPZ; bottom, extre heating required for equilibrium of normal zane (solid line = stable equilit:tium, dashed line $=$ unstable equilibrium).

The MPZ is spherical and has a radius [See Eq. (5) in Ref. 1]

$$
\left.R_{\text {crit }}=\left[3 k\left(T_{j}-T_{o}\right) / j^{2} \rho\right)\right]^{\frac{1}{2}} \text {. }
$$

\section{iii. Stabilj':y Parameter}

With a dimensionless stability parameter

$$
\xi_{j}=k\left(T_{j}-T_{o}\right) /\left(r_{o}^{2}{ }^{2} \rho\right),
$$


one gets the dimensionless formula

$$
R_{\text {crit }} / r_{0}=\left(3 \xi_{j}\right)^{\frac{1}{2}} \text {. }
$$

The stability parameter $\xi_{j}$ is the ratio of heat flowing out of a sphere of radius $r_{0}$ to the Joule heat produced in a sphere of radius $r_{0}$, if the uniform temperature gradient at the surface of the sphere is chosen as $\left(\mathrm{T}_{j}-\mathrm{T}_{0}\right) / 3 \mathrm{r}_{0}$. The choice of this gradient is somewhat arbitrary; it is convenient for the spherical case. (Thus, heat flowing out of sphere: $4 \pi r_{0}^{2} k\left(T_{j}-T_{0}\right) / 3 r_{o}$; heat produced inside: $4 / 3 \pi r_{0 j}^{3} \rho$; quotient is $\left.\xi_{j} \cdot\right)$ The characteristic length $r_{0}$ is also used to render all other quantities dimensionless. The choice of $r_{0}$ is free; it may be taken as $1 \mathrm{~cm}$ or any other convenient length with the exception of zero. The reason for the need of a finite $r_{0}$ is that the extra heating $\dot{Q}$ (see Figure A) cannot be introduced at a point without $T$ and its gradients going to $\infty$. Therefore $r_{0}$ has to be finite, but otherwise the choice of $r_{0}$ is free. It is seen that in the above formula for $R, r_{0}$ cancels on both sides of the equation. of course, when comparing stability parameters under different conditions the radius $r_{0}$, once chosen, must be kept unaltered. It is convenient to have results, as in Figures $B$ to $E$, in reduced dimensionless coordinates. This convenience of dimensionless presentation suits the generality of the results well and is also encompassed in the other geometries discussed below. However, the other geometries have no parameters of fiee choice such as $r_{0}$ which is peculiar to the spherical geometry.

The stability parameter $\xi_{j}$ is useful to comparison of $p^{x}$ :rformance under different operating conditions. especially for the change in operating current. For comparisons between different designs a "stabilization" parameter $\xi_{0}=(k / r b)\left(T_{c}-T_{0}\right) /\left(j_{0}^{2} \rho\right)$, with $j_{0}$ being the critical current density at $\mathrm{T}_{O}$, is more useful. The parameter $\xi_{0}$ characterizes the conductor material; it is independent of the operating current, but depends on the operating temperature $\mathrm{T}_{0}$. For comparisons between different operating temperatures, both parameters are equally useful.

iv. Results for ISABELLE Coil Data

Assume the following values:

Remarks

$$
\begin{array}{ll}
K=0.2 \mathrm{~W} / \mathrm{cm} \mathrm{K}(\text { at } 4.5 \mathrm{~K}) & \begin{array}{l}
\text { transverse (azimuthal) thermal con- } \\
\text { ductivity }
\end{array} \\
j=34 \mathrm{kA} / \mathrm{cm}^{2} & \begin{array}{l}
\text { operating current } \mathrm{I}=4 \mathrm{kA}, \\
\mathrm{A}_{S}=0.117 \mathrm{~cm}^{2}
\end{array} \\
\rho=1.8 \times 10^{-8} \mathrm{~cm} & \text { resistivity of braid } \rho=(1+\lambda) / \rho_{\mathrm{Cu}}
\end{array}
$$




$$
\begin{array}{ll}
\left(j^{2} \rho=20.8 \mathrm{~W} / \mathrm{cm}^{3}\right) & \begin{array}{l}
\lambda=0.8 \text { being SC:Cu ratio; } \\
\rho_{\mathrm{Cu}}=10-8 \Omega \mathrm{cm}
\end{array} \\
\mathrm{T}_{\mathrm{c}}=9.5 \mathrm{~K} & \\
\mathrm{~T}_{\mathrm{j}}=5.1 \mathrm{~K} & \mathrm{I}_{\mathrm{o}}=4.5 \mathrm{kA} \text { at } 4.5 \mathrm{~K}\left(\mathrm{j} / \mathrm{j}_{\mathrm{o}}=0.89\right) \\
\mathrm{j}_{\mathrm{o}}=38.5 \mathrm{kA} / \mathrm{cm}^{2}(4.5 \mathrm{~K}) & \mathrm{I}_{\mathrm{o}}=5.2 \mathrm{kA} \text { at } 3.8 \mathrm{~K}\left(\mathrm{j} / \mathrm{j}_{0}=0.77\right) \\
\mathrm{j}_{0}=44.4 \mathrm{kA} / \mathrm{cm}^{2}(3.8 \mathrm{~K}) & \\
\left.\mathrm{j}_{\mathrm{sco}}=100 \mathrm{kA} / \mathrm{cm}^{2}\right) & \text { free choice }\left[\text { to make } \xi_{\mathrm{j}}(4.5 \mathrm{~K})=2\right] \\
\mathrm{r}_{\mathrm{o}}=0.054 \mathrm{~cm} &
\end{array}
$$

One gets the parameters characterizing stability:

$$
\begin{array}{llll} 
& & 4.5 \mathrm{~K} & 3.8 \mathrm{~K} \\
& 2 & 3.9 \\
\xi_{\mathrm{o}} & = & 13 & 10
\end{array}
$$

Figure B (Figure 7, Ref. 1) gives the size of the MPZ and indicates extra heating needed for smaller normal zones. The curves divide stable operating region, below, from unstable operating region, above the curves.

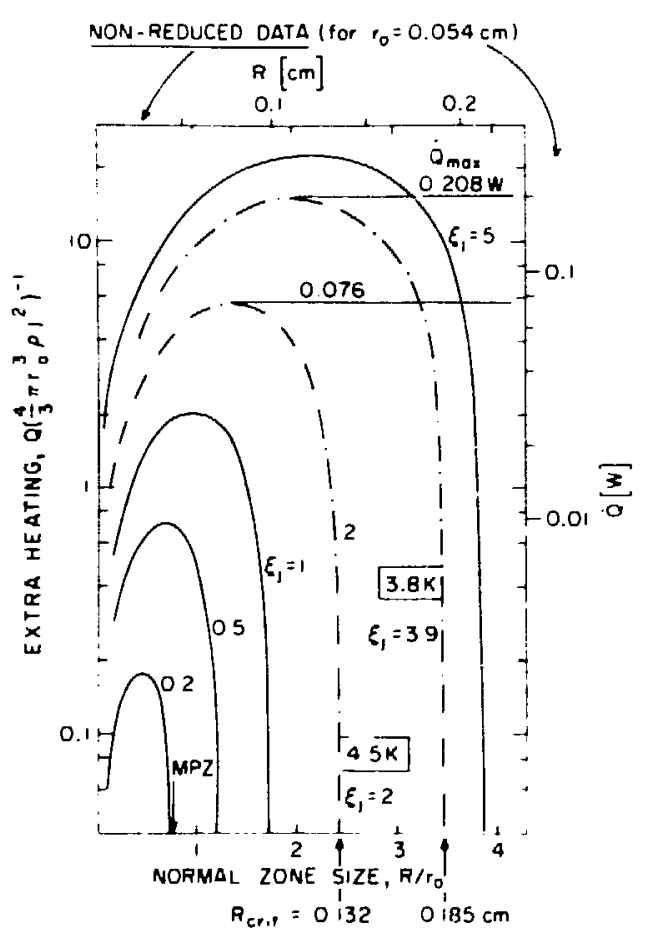

Figure B Spharical case: extra heating for ti:ormal equilibrium as a function of normal zone size for different stability parameters $\xi_{0}=\left(k / r_{0}^{2}\right)\left(T_{j}-T_{o}\right) / j^{2} p$. 
Figure $C$ gives the size of the MPZ versus the operating current.

Figure $D$ is a linear plot of Figure $C$.

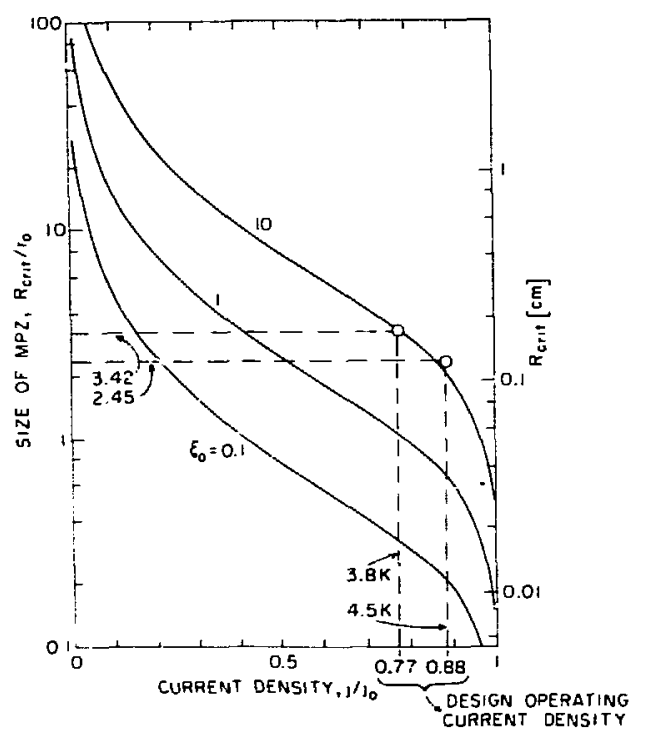

Figure C Spherical case: size of MPZ as functicn of current density for different stabilization parameters $\xi_{\mathrm{o}}=\left(\mathrm{k} / \mathrm{r}_{\mathrm{o}}^{2}\right)\left[\left(\mathrm{T}_{\mathrm{c}}-\right.\right.$ $\mathrm{T}_{\mathrm{o}}$ ) $/ \mathrm{j}_{\mathrm{o}}^{2} \mathrm{p}$ ] (cf. Figures 12 and 32 in Ref. 1).

The amount of heat release necessary to create the MPZ is, rough1y, proportional to the volume of the $\mathrm{MPZ}$. Such heat releases, of course, are to be considered as the imperfections that spoil the performance of the coil. Figure $E$ with current versus MPZ volume is therefore a plot of performance versus imperfections. Similar plots of performance versus imperfections are found to be general features for many highly optimized devices where stability becomes a problem. A classical example is the buckling of highly stressed structures (see Figıre 17, Ref. 1).

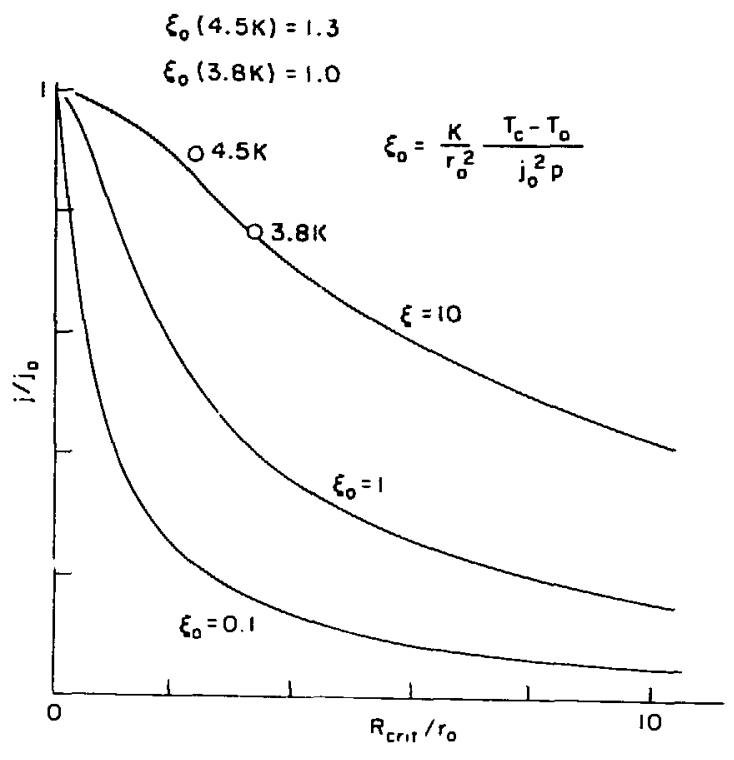

MPZ

Figure D

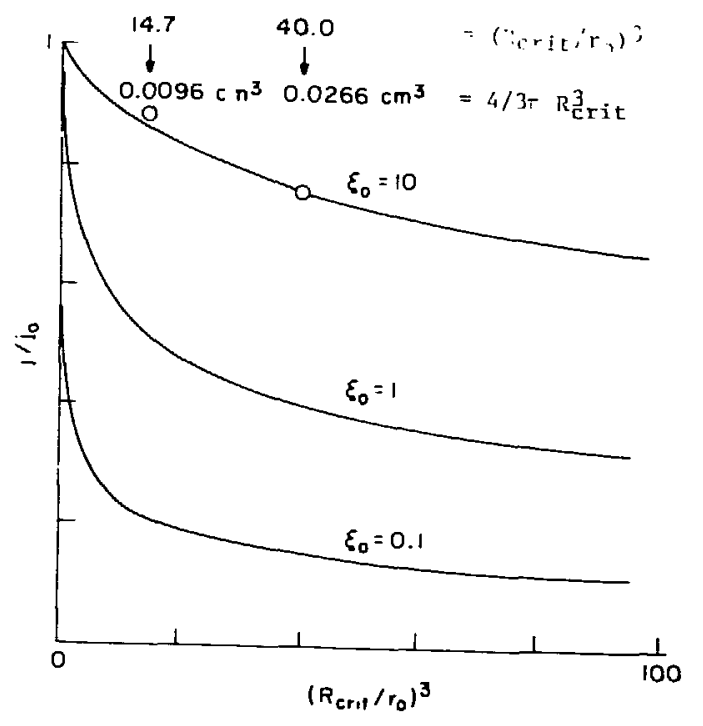

MPZ

Figure E 
v. Adjustments for Nonisotropic Thermal Conduction

The spherical geometry calculation gives an idea of how small MPZs are compared to the dimensions of the winding blocks. Therefore, apart from the assumption of isotropic thermal conductivity, the spherical approximation may be more reasonable than expected. But it is quite clear that the thermal conductivity parallel to the current density is man:y times more than the one transverse to it. Reasonable values are: $\mathrm{k}_{\|}=3 \mathrm{~W} / \mathrm{cm} \mathrm{K}$ and $\mathrm{k}_{1}=0.2 \mathrm{~W} / \mathrm{cm} \mathrm{K}$.

Martin Wilson found that the spherical approximation is quite suitable for potted high current density coils. He extended the calculation by making a suitable transformation between spherical and cylindrical coordinates ${ }^{2}$ and finds for the MPZ an ellipsoid with the main axis

$r_{i}^{2}=3 k_{i}\left(T_{j}-T_{0}\right) /\left(j^{2} \rho\right)$

Its volume

$$
4 \pi r_{1} r_{2} r_{3} / 3
$$

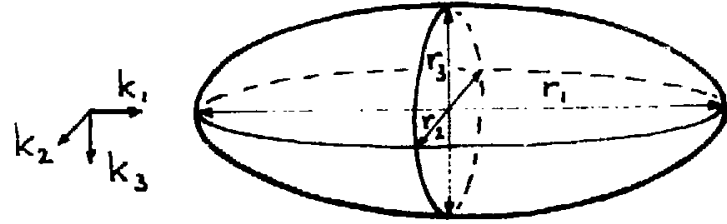

$k_{1}=k_{11} ; \quad k_{2}=k_{3}=k_{1}$

will be $\sqrt{k_{\|} / k_{1}}$ times larger than in the previous spherical case (or approximately 4 times).

With the above values (s. p. 4) and $k_{1}=k_{\|}=3 \mathrm{~W} / \mathrm{cm} \mathrm{K} ; \mathrm{k}_{2}=\mathrm{k}_{3}=$ $\mathrm{k}_{\perp}=0.2 \mathrm{~W} / \mathrm{cm} \mathrm{K}$ at $4.5 \mathrm{~K}$, one gets:

$$
r_{1}=5 \mathrm{~mm}, r_{2}=r_{3}=1.3 \mathrm{~mm} ; \text { volume }=3.5 \times 10^{-2} \mathrm{~cm}^{3} ;
$$

(surface $=66 \mathrm{~mm}^{2}$ ) or, with $\mathrm{k}_{3}=1 \mathrm{~W} / \mathrm{cm} \mathrm{K}: \mathrm{r}_{3}=2.9 \mathrm{~mm}$, volume $=0.08$ $\mathrm{cm}^{3}$ (surface $=110 \mathrm{~mm}^{2}$ ).

At $3.8 \mathrm{~K}: \mathrm{k}_{1}=2.5 \mathrm{~W} / \mathrm{cm} \mathrm{K}, \mathrm{k}_{2}=\mathrm{k}_{3}=0.18 \mathrm{~W} / \mathrm{cm} \mathrm{K}$ :

$$
r_{1}=7 \mathrm{~mm}, r_{2}=r_{3}=1.8 \mathrm{~mm} \text {, volume }=0.1 \mathrm{~cm}^{3} \text {. }
$$

Or, with $\mathrm{k}_{3}=0.85 \mathrm{~W} / \mathrm{cm} \mathrm{K}: \mathrm{r}_{3}=4 \mathrm{~mm}$ and volume $=0.21 \mathrm{~cm}^{3}$.

2. M.N. Wilson, Energy needed to create Minimum Propagating Zones, Rutherford Laboratory, Note SMR/25, 1977. 
vi. An Equally Suitable Geometry Is the "Transmission Line Case"

The transmission line geometry still allows one-dimensioral calculations. In the spherical case heat is removed by conduction only; here cooling across a surface into a cooling medium is assumed. Figure $F$ (Figure 10, Ref. 1) illustrates this geometry. It is assumed that thermal conduction within the conductor is sufficiently high that thermal gradients in the cross section of the conductor can be neglected.

In the ISABELLE coil, a whole current block can be taken as a transmission line with $2 \mathrm{r} \approx 1.83 \mathrm{~cm}$. Again, the MPZ is given by a steadystate temperature distribution found by balancing the heat production with the heat losses. The results are displayed in Figure $G$ corresponding to Figure $B$, and Figure $H$ corresponding to Figure $C$.

A significant difference between spherical and transmission line geometry is that the MPZ becomes infinice for $\xi_{j}=0.5$, and $\xi_{j}>0.5$ no MPZ exists. In the spherical case, the MPZ is finite for all values of $\xi_{j}$. In passing, it may be mentioned that for $\xi_{j}>$ the stability is global, i.e., there is only one basin of attraction, and the superconducting state is fully regained no matter how big a disturbance is assumed, even after the whole device is made fully normal (always provided, of course, that the parameters do not change enough to alter the condition $\left.\xi_{j}>1\right)$. For $0.5<\xi_{j}<1$, the stability is only slightly less: the device recovers, provided that superconducting regions of sufficient size, minimum recovery zones (MRZ), are maintained during a disturbance. The MRZ is zero for $\xi_{j}=1$ and infinite for $\xi_{j}=0.5$.

Another difference is that the maximum of extra heating is for a normal zone of zero length. This means, that if the disturbance is a steady heat source (e.g., a resistive joint) there is either no normal zone at all or a quench. 
(a)

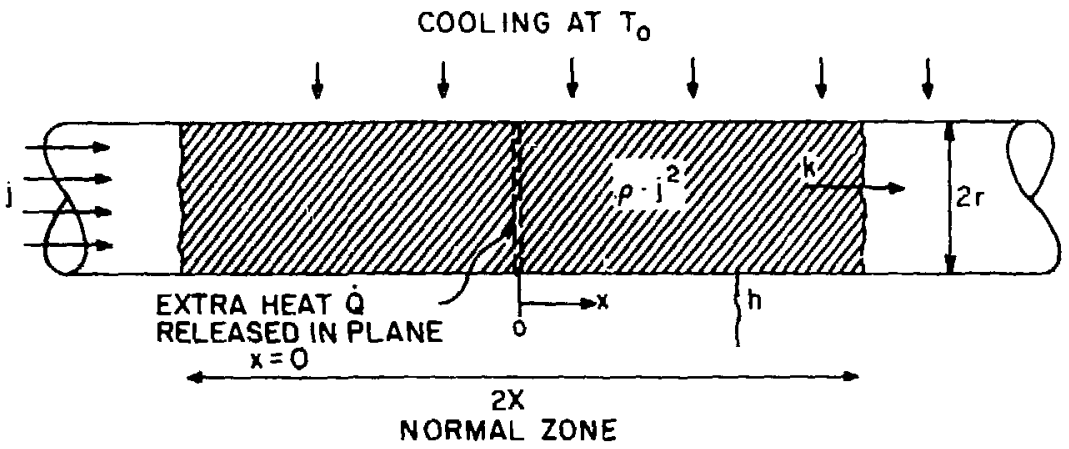

(b)

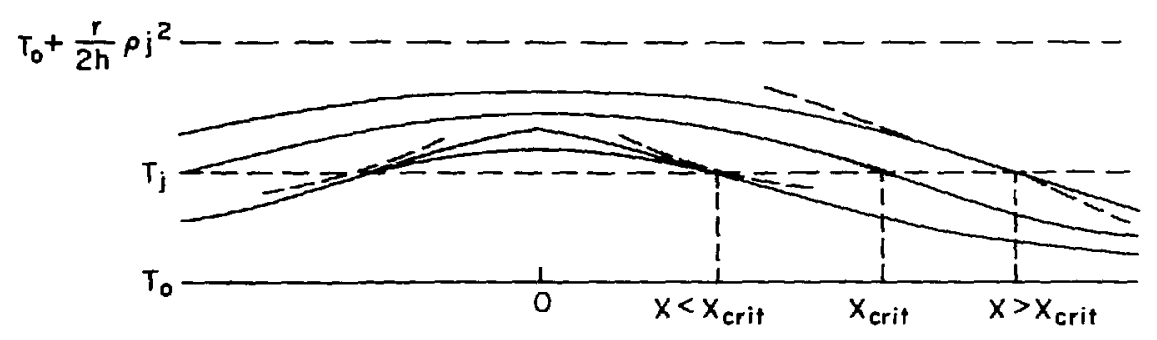

(c)

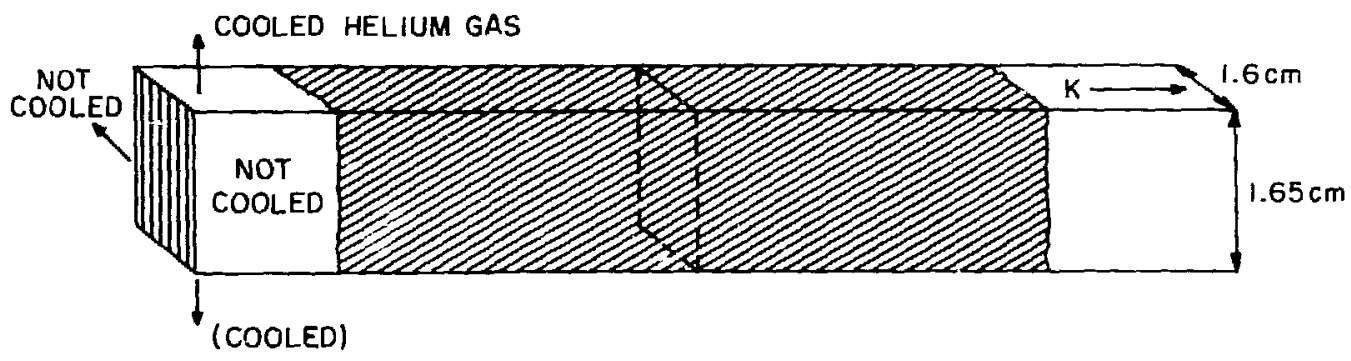

ISABELLE COIL CURRENT BLOCK

Figure $F$

Transmission line geometry. (a) Nomenclature. (b) Equilibrium temperatur: Cistributions, inside and outside normal zone. $\mathrm{X}>\mathrm{X}_{\text {crit, tangent at } \mathrm{X} \text { not }}$ matching; $\mathrm{X}=\mathrm{X}_{\text {crit }}, \mathrm{MPZ} ; \mathrm{X}<\mathrm{X}_{\text {crit, }}$ tangent $\mathrm{zt} \mathrm{X}$ matching with extra heating at $\mathrm{x}=0$. (c) Transmission line geometry applied to ISABELLE coil current block. 


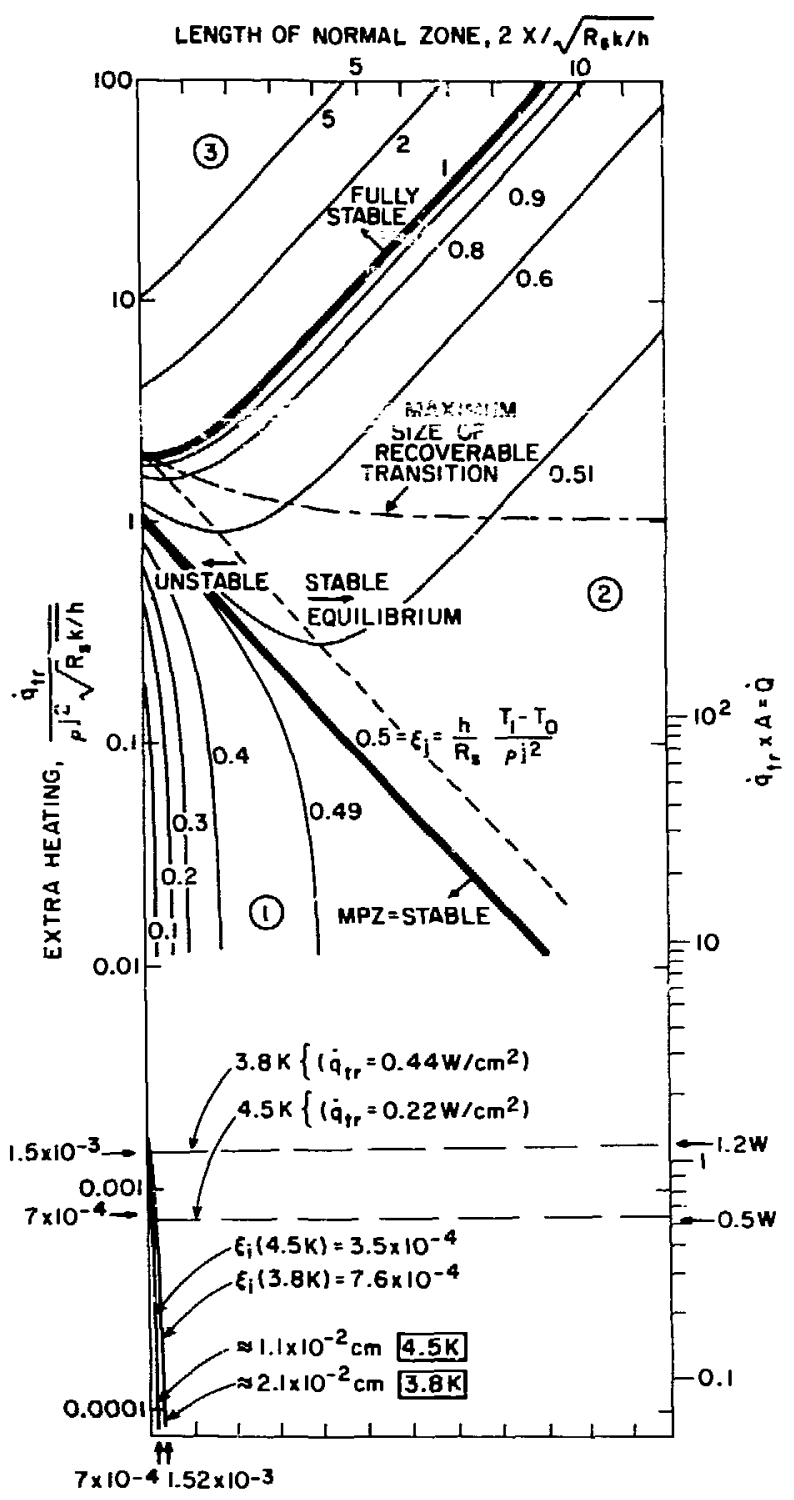

Figure G

Extra heating at $\mathrm{x}=0$ for thermal equilibrium of normal zone. Curves for different stability parameters $\xi_{j}=\left(h / R_{S}\right)\left[\left(T_{1}-T_{0}\right) / j 2 \rho\right]$. Dashed straight line = locus of minima; gives boundary between unstable and possible stable equilibria. Dot-dash line $=$ maximum size of (recoverabie) transition for $0.5<\xi_{j}<1$, given by $\mathrm{x} / \mathrm{a}=$ $-\ln \left(2 \xi_{j}-1\right)$, obtained from Eq. (31). Circled numbers 1,2 , and 3 indicate regions (bounded by the thick curves, $\xi_{j}=0.5,1$ ) of MPZ stability, MRZ stability, and full stability, respectively.

A: cross section of conductor (conductor is whole current block)

$R_{S}$ : cross section/cooled perimeter

$\sqrt{\mathrm{R}_{\mathrm{S}} \mathrm{k} / \mathrm{h}:}$ characteristic length $=14 \mathrm{~cm}$ (at $\left.3.8 \mathrm{~K}\right)$

assume $h=0.02 \mathrm{~W} / \mathrm{cm}^{2} \mathrm{~K}$

$$
=15 \mathrm{~cm} \text { (at } 4.5 \mathrm{~K} \text { ) }
$$




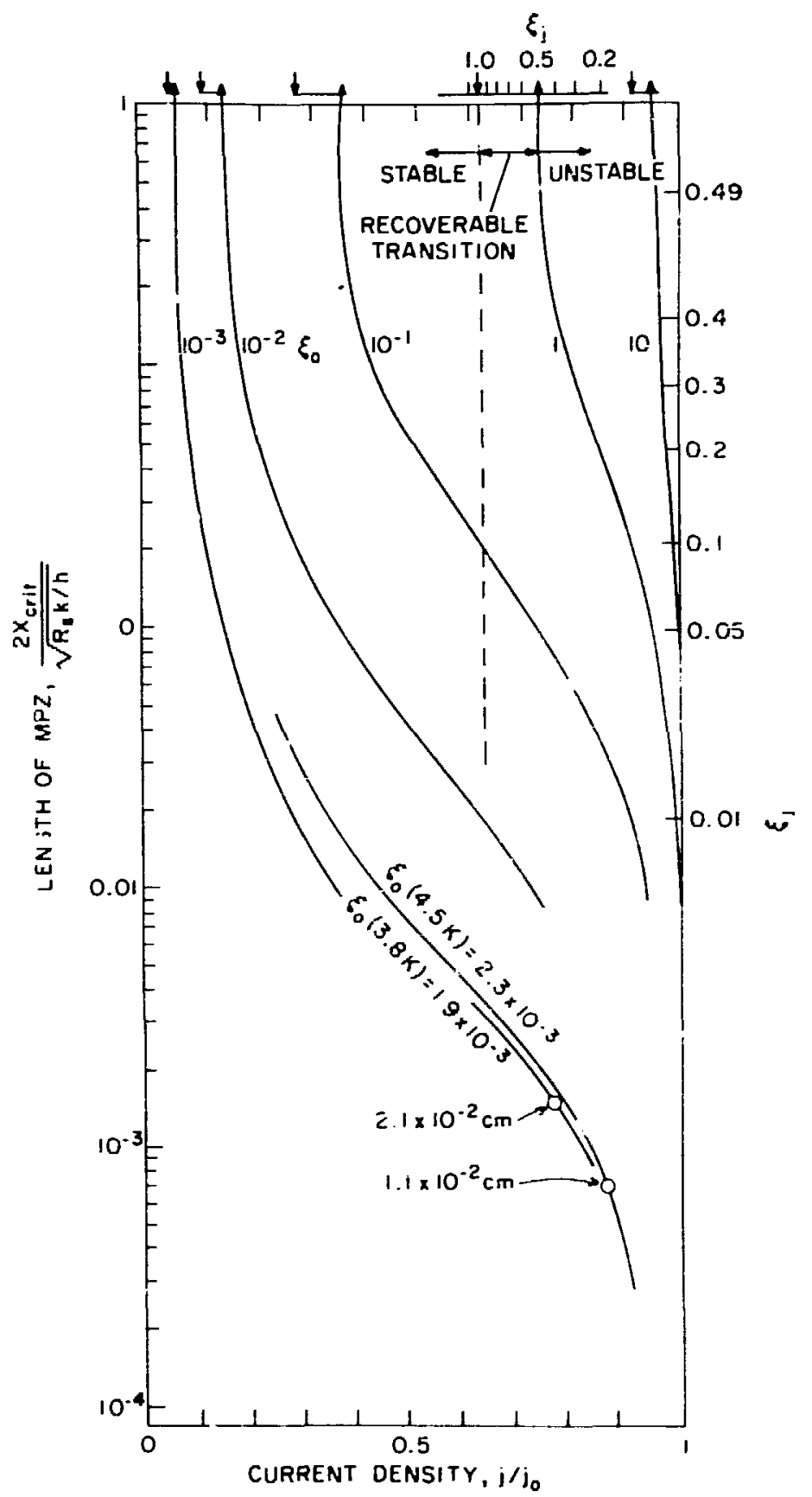

Figure $\mathrm{H}$

Size of MPZ as function of current density. Curves for different stabilization: parameter $\left.\xi_{0}=\left(h / R_{s}\right)\left[T_{c}-T_{0}\right) / j_{0}^{2} \rho\right]$. Values on right indicate the ctabil:t: parameter $\xi_{j}$. For $\xi_{0}=1$ only, the values for $\varepsilon_{j}$ are also indicated at the top, together with the stability region. $\uparrow$ gives $\varepsilon_{j}=0.5 ; !$ gives $\tau_{j}=1$. 
The following numerical values for the ISABELLE coils are used:

Remarks

$$
\begin{aligned}
& R_{S}=2.64 / 1.6=3.55 \mathrm{~cm} \\
& h=0.02 \mathrm{~W} / \mathrm{cm}^{-2} \mathrm{k}^{-?}
\end{aligned}
$$

$\mathrm{k}(4.5 \mathrm{~K})=2.8 \mathrm{~W} / \mathrm{cm} \mathrm{K}$

$k(3.8 \mathrm{k})=2.3 \mathrm{~W} / \mathrm{cm} \mathrm{K}$

$\mathrm{a}(4.5 \mathrm{~K})=15.2 \mathrm{~cm}$

$\mathrm{a}(3.8 \mathrm{~K})=14 \mathrm{~cm}$

j $(4.5 \mathrm{~K})=3.5 \times 10^{-4}$

$\xi_{j}(3.8 \mathrm{~K})=7.6 \times 10^{-4}$

$\xi_{0}(4.5 \mathrm{k})=2.3 \times 10^{-3}$

$5_{0}(3.8 \mathrm{k})=1.9 \times 10^{-3}$

$E_{0}=1.9 \mathrm{~J}$
$R_{S}=$ cross section/cooled perimeter

heat transfer coefficient (an es-

timate; cooling into almost stag-

nant helium gas is not well known)

longitucinal thermal conductivity

characteristic lengtr $a=\left(R_{s} k / h\right)^{\frac{1}{2}}$

$\xi_{j}=\frac{h}{R_{s}} \frac{T_{j}-T_{0}}{j^{2} \rho}$

$\Sigma_{c}=h / R_{i} T_{c}-T_{o} / j_{o}^{2} \rho$

$E_{O}$ : enthalpy difference to raise piece of iength a (volume aAc $z$ $40 \mathrm{~cm}^{3}$ ) from $T_{0}$ to $T_{c}$ :

$E_{0}=A_{c} a \int_{T_{0}}^{T_{C}} c d T$

Using $c=10^{-4}\left(\mathrm{~J} / \mathrm{cm}^{3} \mathrm{k}^{3.3}\right) \mathrm{T}$

(measured for a coil composite)

one gets $\int_{4.5}^{9} \mathrm{~d} \mathrm{dT}=0.047 \mathrm{~J} / \mathrm{cm}^{3}$

For a yalue of $j \geq 0.5$ (:RR-, or cryostatic stability) the current needs to be $\mathrm{I}=105 \mathrm{~A}$ at $4.5 \mathrm{~K}$ and $\leq 155 \mathrm{~A}$ at $3.8 \mathrm{~K}$.

vi.i. Comparison Becween Spherical and Transmis: ion Line Geometry

The stability parameters are sutficiently small that (for transm.

1. gicom.) $: P Z=2 a ; j$ [see Eq. (32')] and

$: P Z(4.5 \mathrm{~K}): 7 \times 10-4 \times 15=0.01 \mathrm{~cm}$

IP7 (3.8 K) : $1.52 \times 10^{-3} \times 14=0.021 \mathrm{~cm}$

volume $(4.5 \mathrm{~K}): 0.028 \mathrm{~cm}^{3}$

valume $(3.8 \mathrm{~K}): 0.055 \mathrm{~cm}^{3}$

These resuits compare favorably with those of the spherical geometry: 


$$
\begin{array}{lll}
R_{\text {crit }}(4.5 \mathrm{~K})=0.13 \mathrm{~cm} & \text { volume }=0.01 \mathrm{~cm}^{3} \\
R_{\text {crit }}(3.8 \mathrm{~K})=0.19 \mathrm{~cm} & \text { volume }=0.028 \mathrm{~cm}^{3}
\end{array}
$$

Corre, ted for anisotropic K:

$$
\begin{aligned}
& \text { volume } \operatorname{RPZ}(4.5 \mathrm{~K})=0.08 \mathrm{~cm}^{3} \\
& \text { volume } \mathrm{APZ}(3.8 \mathrm{~K})=0.21 \mathrm{~cm}^{3}
\end{aligned}
$$

Even though the shape of the MPZ in the two geometries is entirely different (cigar shaped in the spherical geometry, very short cylinder in the transmission 1 in ( geometry), tr 2 rolumes are of the same order of magnituda.

A plausible shape for the "raal" MPZ, as applicable to the ISABELLE windinge, is a cigar shape, with parts of one (or two neighboring) braid in the normal ; rate, as sketched below.

The Joule heating power produced in the resistive IPZ is approximately $0.6 \mathrm{H}$ and corpares with the extra heating needed to create an SPZ of zero volume (see Figure G).

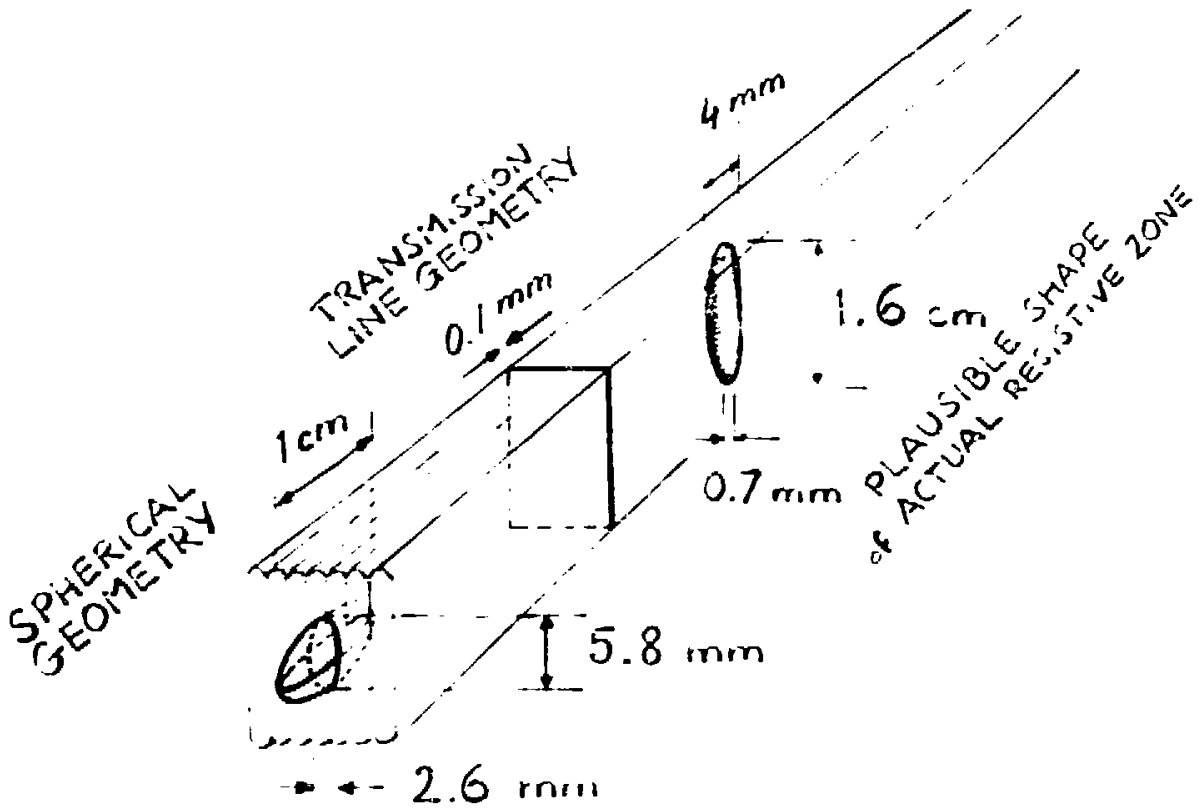




\section{ABOUT DISTUPBANCES}

\section{i. Energy Needed To Create the MPZ}

The resistive part of the MPZ is very small (volume at $4.5 \mathrm{~K}$ of the order of $\left.0.03 \mathrm{~cm}^{3}\right)$. Its enthalpy difference $\left(\left\{5^{1} \mathrm{c} \mathrm{dT} \approx 2.2 \mathrm{~mJ} / \mathrm{cm}^{3}\right)\right.$ is only about $70 \mu \mathrm{J}$. However, when considering the energy needed to create the IPZ one has to take into account the enthalpy difference of the entire temperature distribution associated with the MPZ, and that enthalpy difference usually is orders of magnitude larger than the enthalpy of just the resistive zone (see Figure 15b, Ref. 1).

In the transmission 1 ine geometry the temperature distribution associated with the MPZ has a finite enthalpy difference* to the undisturbed state, and can be calculated as in the plot Figure I.

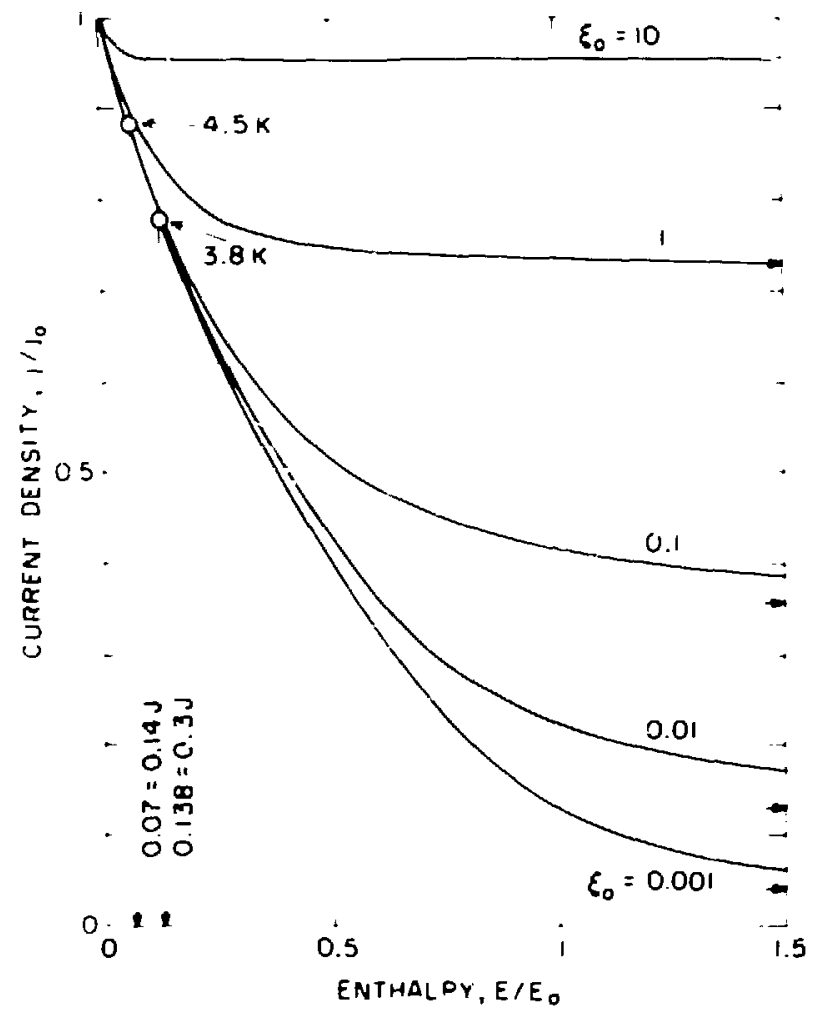

Figure I Enthalpy of MPZ temperature distribution (without current sharing).

*in the spherical case the enthalpy becomes infinite. 
So far, all calculations were for the noncurrent sharing case, where $\rho=0$ for $T<T_{j}$ and $\rho=\rho_{n}$ for $T>T_{j}$. In case of current sharing, $\rho=\rho_{n}\left(T_{c}-T_{0}\right) /\left(T_{c}-T_{j}\right)$ for $T_{j}<T<T_{c}$. The calculations are more complicated but the final results are little different; Figure $J$ (Figure $33 \mathrm{~b}$, Ref. 1) shows this for the enthalpy of the MPZ. The difference between current sharing and noncurrent sharing is vanishing at $\xi_{0}<0.001$, as can be seen by comparing Figure $J$ with Figure $I$, and also in Figure 29 of Ref. 1 .

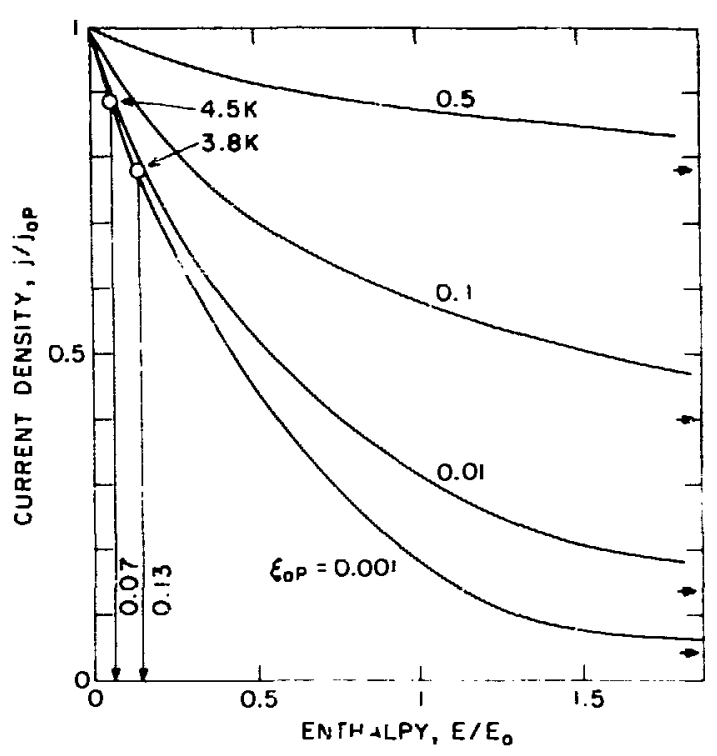

Figure : Enthalpy of MPZ temperature distribution (with current sharing).

For sma11 values of the stability parameters, the resistive part of the MPZ is very small compared to the whole MPZ temperature distribution, which is why its particular shape is not very important.

\section{ii. What Kind of Disturbance Will Cause a Quench?}

If a disturbance is in the form of a localized steady heat input (isothermal disturbance), it will cause a quench if it exceeds the maximum values indicated in Figures $B$ and $G$ :

$\begin{array}{lll}\text { at } 4.5 \mathrm{~K} & 0.36 \mathrm{~W} \text { (spherica1) or } 0.5 \mathrm{~W} \text { (transm. 1ine) } \\ \text { at } 3.8 \mathrm{~K} & 1.1 \mathrm{~W} \text { (spherical) or } \mathrm{i} .2 \mathrm{~W} \text { (transm. 1ine) }\end{array}$

(In the spherical case, at $4.5 \mathrm{~K}, \dot{\mathrm{Q}}_{\max }=0.076 \mathrm{~W}$. For the anisotropic cigar shaped MPZ this is higher. If it scales like the surface of the resistive zone, $\dot{Q}_{\max }$ becomes $0.22 \mathrm{~W}$ for the ellipsoid with $\mathrm{r}_{2}=\mathrm{r}_{3}=$ $1.3 \mathrm{~mm}$, and $0.36 \mathrm{~W}$ 아 the one with $r_{3}=2.9 \mathrm{~mm}$. ) 
If a disturbance $j s$ in the form of a localized, sudaen heat release (adiabatic disturbance), the size that leads to a quench is indicated in Figure I or $\mathrm{J}$ :

$$
\begin{array}{lll}
\text { at } 4.5 \mathrm{~K} & 0.14 \mathrm{~J} \\
\text { at } 3.8 \mathrm{~K} & 0.3 \mathrm{~J}
\end{array}
$$

always provided that the local extent of the discurbance is comparable with the extent of the $\mathbb{P P Z}$ tenperature distribution. For a narrowly localized source (such as a heater) a very much smalier energy will. lead to a quench, but it will always need more than the $70 \mu \mathrm{J}$ mentioned above (beginning paragraph of previous subsection).

We conclude that in going from 4.5 to $3.8 \mathrm{~K}$ the coil at the operating current can stand, roughly, disturbances of twice the size. If the disturbances are independent of temperature, we see from Figure I or $\mathrm{J}$ that a coil quenching at $4.5 \mathrm{~K}$ at $\mathrm{j}=0.8 \mathrm{jo}(4.5 \mathrm{~K})$ is $\perp$ ikely to quench at $3.8 \mathrm{~K}$ at $j=0.8 j_{0}(3.8 \mathrm{~K})=0.9 j_{0}(4.5 \mathrm{~K})$. However, the disturbances are almost certain to increast: with increasing magnetic field.

\section{iii. Comparison With ISABELLE Dipole Performance}

The ISABELLE dipole performance is illustrated in Figure K. Comparison with above results shows that the initial quenches are caused by the equivalent of adiabatic disturbances of $0.5 \mathrm{~J}$. With progressive training, the disturbances drop to $0.2 \mathrm{~J}$.

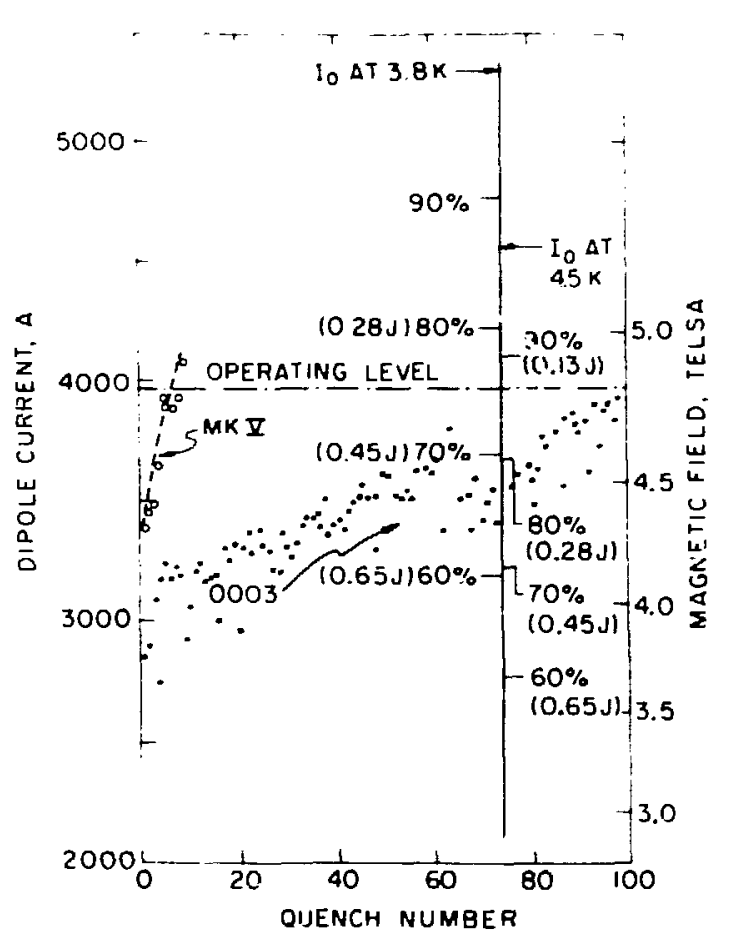

Figure $\mathrm{K}$

Typical performance of ISABELLE dipole. Indication of short sample current $I_{0}$, and energy of adiabatic disturbance causing a quench, for 4.5 and $3.8 \mathrm{~K}$. 
It is fairly safe to assume that ISABELLE coils quench because of adiabatic and not because of isothermal disturbances. Furthermore, it is reasonable to assume that the disturbances are not strongly dependent on temperature. Therefore, ISABELLE coils operated at $3.8 \mathrm{~K}$ are expected to reach currents approximately $10 \%$ higher than at $4.5 \mathrm{~K}$. This difference should be seen if a coil had several training steps at $4.5 \mathrm{~K}$ and subsequent $1 \mathrm{y}$ a number of training quenches at $3.8 \mathrm{~K}$; returning to $4.5 \mathrm{~K}$ should lower the quench current again.

\section{WHAT ELSE IF THERE TO SAY ABOUT STABILITY?}

i. Could Some Improvement Be Gained by Changing the Cu:SC ratio?

Increasing the ratio of $\mathrm{Cu}: \mathrm{SC}$ will reduce $\lambda$, thus improving stability. But it also decreases $j_{0}$ and thus performance (unless: of course, the winding cross section is enlarged). The total effect is illustrated in Figure L. Quantitative results for ISABELLE dipoles have been entered. It is observed that for a given adiabatic disturbance there is a very flat maximum ir performance. For small disturbances the maximum is at low ratio of $\mathrm{Cu}$ :SC. Consequently, small high current density coils are designed with low $\mathrm{Cu}$ content. An optimal, economical design uses a Cu:SC ratio to the left of the maximum, as is the case for the ISABELLF coils.

\section{ii. Could Flux Jumps Be of Importance?}

Flux jumps, if they occur, are among the most potent disturbances. The filaments in ISABELLE's multifilament wire have a diameter of $9 \mu \mathrm{m}$. The following flux jump criterion gives a size linit for flux junp Jccurrence [see Eq. (135) on p. 63 of Ref. 1]:

$$
v \leq 8 \mathrm{c} /\left[\mu_{\mathrm{o}} \mathrm{j}_{\mathrm{c}}\left(-\mathrm{dj}_{\mathrm{c}} / \mathrm{dT}\right)\right] \text {, }
$$

with the following values representative at $4.5 \mathrm{~K}$ :

$$
\begin{aligned}
c & =5 \mathrm{~kJ} \mathrm{~m}^{-3} \mathrm{~K}^{-1} \\
\mathrm{j}_{0} & =20 \mathrm{GA} \mathrm{m}^{-2} \\
-\mathrm{dj}_{\mathrm{c}} / \mathrm{dT} & =4 \mathrm{GA} \mathrm{m}^{-2} \mathrm{~K}^{-1} \\
\mu_{0} & =4 \pi \times 10^{-7} \mathrm{VsA}^{-1} \mathrm{~m}^{-1}
\end{aligned}
$$

a limiting value of $w(4.5 \mathrm{k}) \leq 20 \mu \mathrm{m}$ is obtained. Lowering the temperature to 3.8 will decrease $c$ by $-40 \%$ if $c \propto \mathrm{T}^{-2}$, or by $-66 \%$ if $c \propto \mathrm{T}^{-3}$; $\mathrm{j}_{\mathrm{c}}$ is changed by $+15 \%$; $\mathrm{dj}_{\mathrm{c}} / \mathrm{dT}$ is unchanged. With these values ( $c=3.6$ or $3.0 \mathrm{~kJ} \mathrm{~m}^{-3} \mathrm{~K}-1$ and $\left.j_{c}=23 \mathrm{GA} \mathrm{m}^{-2}\right)$, the limiting thickness of $\mathrm{w}(3.8 \mathrm{~K})=$ 16 or $14 \mu \mathrm{m}$ is obtained. Another, similar test is a comparison between the field needed to penetrate a 9- $\mu \mathrm{m}$ wire completely and the flux jump field. The penetration field is $\mu_{o} j_{c} w / 2 \& 1.13 \mathrm{kG}$; the flux jump field is $\left[2 \mu_{o} c j_{c} /\right.$ $(-d j c / d T)]^{\frac{1}{2}} \approx 2.5 \mathrm{kG}$. With $B_{f j}>B_{\text {pen }}$ there are no flux jumps. Both tests indicate that $\{$ :iere is no flux jump danger.*

\footnotetext{
*For very fast ramp rates even multifilament wire can be subject to flux jumping again. See references by B. Turck.
} 


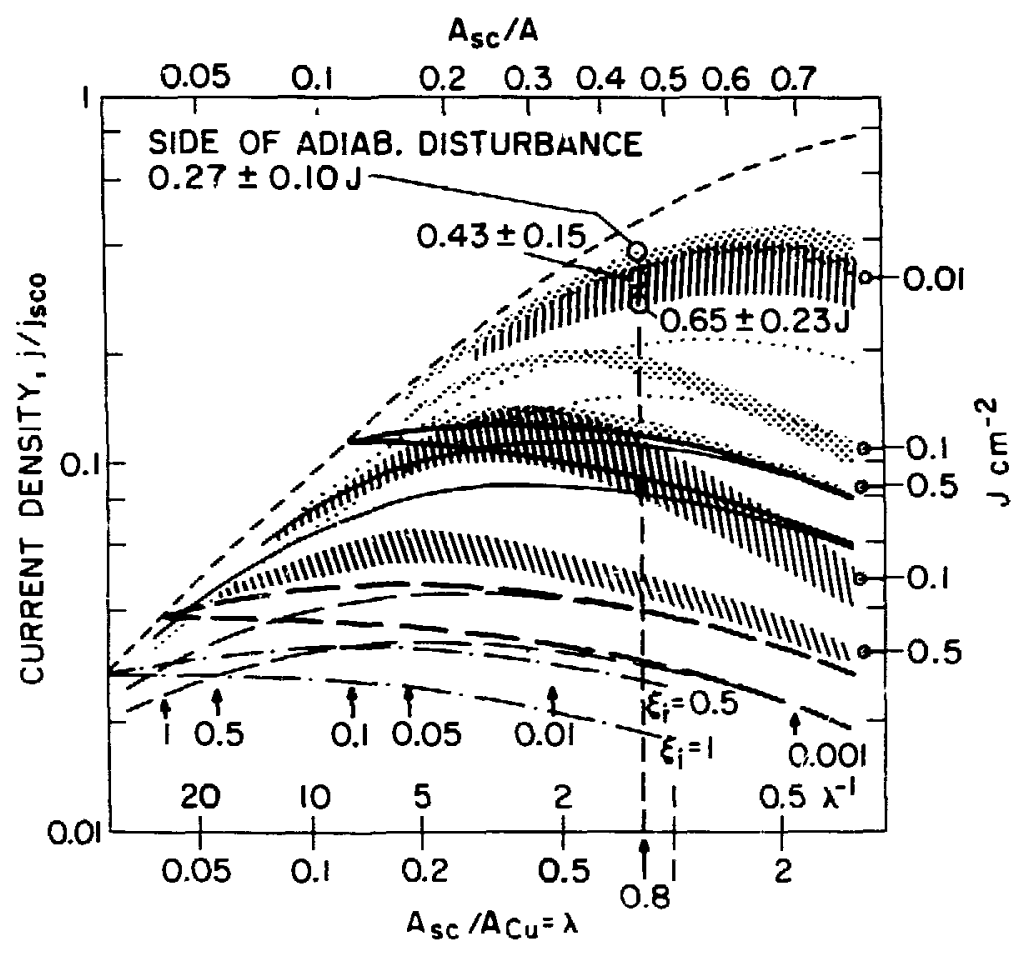

Figuro $\mathrm{L}$ Stability boundaries in composites. Examples for $\rho \mathrm{Cu}=10^{-8} \Omega$

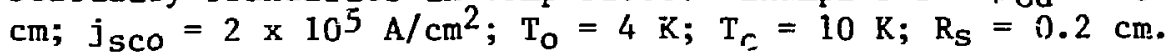
$R_{S}=1.6 \mathrm{~cm}$ for ISABELIE.

--- Short-sample critical current density. Boundary for full stability (lower curve) and $\mathrm{MPZ} \rightarrow \infty$ (upper curve) for ideal current sharing. Same boundaries for noncurrent sharing.

Upper set of curves (solid) applies to $\mathrm{h}=0.2 \mathrm{~W} / \mathrm{cm}^{2} \mathrm{~K}$ (nucleate boiling), lower set (long-dashed curves) to $h=0.2 \mathrm{~W} / \mathrm{cm}^{2} \mathrm{~K}$ (film boiling).

::!: Quench region for adiabatic localized disturbances of 0.5 , $0.1,0.01 \mathrm{~J} / \mathrm{cm}^{2}$ (energy per unit cross section of conductor), as shown on the right. Upper edge of the bands refers to $\mathrm{k}_{\mathrm{Cu}}=10 \mathrm{~W} / \mathrm{cm} \mathrm{K}$ (clean copper), the lower edge to $\mathrm{k}_{\mathrm{Cu}}=2$ $\mathrm{W} / \mathrm{cm} \mathrm{K}$ (dirty copper). Heat transfer coefficient $\mathrm{h}=0.2$ $\mathrm{W} / \mathrm{cm}^{2} \mathrm{~K}$.

$/ / / / /$ Quench region for $\mathrm{h}=0.2 \mathrm{~W} / \mathrm{cm}^{2} \mathrm{~K}$.

.... Upper edge of quench region for $0.02 \mathrm{~J} / \mathrm{cm}^{2}$ but for noncurrent sharing; $\mathrm{h}-0.2 \mathrm{~W} / \mathrm{cm}^{2} \mathrm{~K}$.

.... Same for $\mathrm{h}=0.02 \mathrm{~W} / \mathrm{cm}^{2} \mathrm{~K}$.

$\uparrow$ Values for $\xi_{0}$ for $h=0.02 \mathrm{~W} / \mathrm{cm}^{2} \mathrm{~K}$ ( $\xi_{0}$ is 10 times higher for the higher value of $h$ ).

Indication of adiabatic disturbances to quench ISABELLE coils. Assume $\mathrm{k}_{\mathrm{Cu}}=5 \mathrm{~W} / \mathrm{cm} \mathrm{K} ; \pm$ indizates limits of $\mathrm{k}_{\mathrm{Cu}}=10 \mathrm{~W} / \mathrm{cm} \mathrm{K}$ (+) and $\mathrm{k}_{\mathrm{Cu}}=2 \mathrm{~W} / \mathrm{cm} \mathrm{K}(-)$. 
iii. Lyapunov Functions - Stability Represented by Means of a Generalized Potential Trough

Mechanical equilibria and their stability are often described by the potential energy function in the neighborhood of the equilibrium.

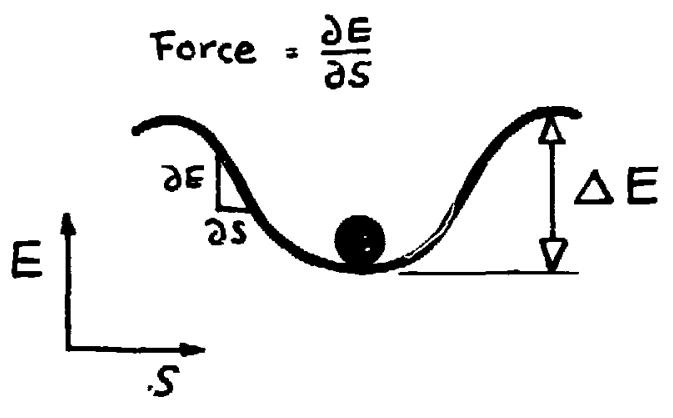

Thus the "basin of attraction" (BOA) of an equilibr:u- situation is illustrated. Measures for the strength of the stability are the depth $\triangle E$ of the BOA and the steepness of its wall $\partial \mathrm{E} / \partial \mathrm{s}$ (restoring force). For a superconductor the $\triangle E$ becomes the enthalpy of an MPZ temperature distribution; the force corresponds to the extra heating. A generalized energy function describing stability is called a Lyapunov function. An attempt to illustrate the stability of a superconducting device by means of such a function is given in Figure 42 of Ref. 1. Such a diagram could be calculated for the ISABELLE coils for 4.5 and $3.8 \mathrm{~K}$. So far I have not done this. Such a diagram would simply combine all the information now given in Figures $G, H, \&$ J into one diagram.

\section{GUESSING THE LIMITATTONS OF THE ISABELLE DIPOLE PERFORMANCE}

\section{i. Possible Disturbances in the ISABELLE Coils}

Coils that exhibit training usually suffer from adiabatic disturbances. Most adiabatic disturbances are of a mechanical nature and they draw their energy from the stored energy in the stressed structure; the mechanical stored energy, in turn, depends on the magnetic stored energy. Therefore, adiabatic disturbances are usually related to the overall stored energy of a magnet. This is reflected in the well-known trend among successful superconducting coils: that the larger a coils is in terms of stored magnetic energy, the smaller the overall current density. (See Figure 40, Ref. 1.) ISABELLE coils with a stored energy of $1 \mathrm{MJ}$ and an average current density of 20 to $30 \mathrm{kA} / \mathrm{cm}^{2}$ (it depends what cross section is used to form $j_{a v}$ ) is near the limit of the state-of-the-art.

In the absence of experimental information on location and extent of quenches, especially on the location relative to previous quenches, one can but guess that the dominant disturbances are mechanical movements of the windings. 
ii. Most Likely Dominant Disturbance in ISABELLE Dipoles: Azimuthal Stick-Slip Movement

The windings are well constrained against radial movement. The constraints against az muthal movement consist of epoxy bonds and friction, yet the azinuthal forces are quite considerable as a very simplified calculation in Table I shows. The stick-slip movement of the windings is away from the poles towards the equator as indicated in Figure M.

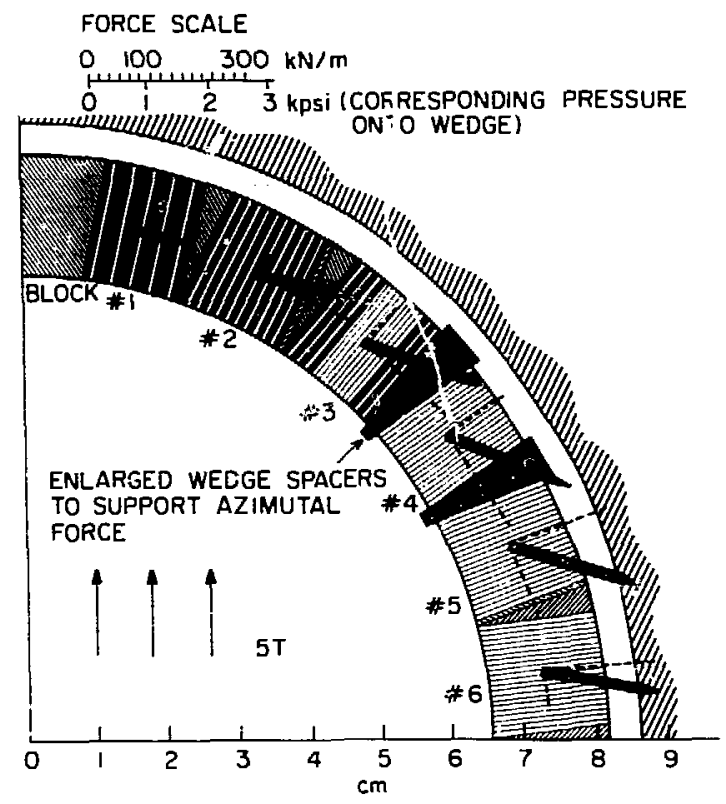

$$
\begin{aligned}
& \text { Figure } M \text { Lpproximate Lorentz forces } \\
& \text { scting on current blocks } \\
& \text { cif dipole. }
\end{aligned}
$$

The bottom line in Table I gives the worst possible energy release, namely, the energy dissipated if the windings move all at once, i.e., if, close to the design operating current, all bonds preventing azimuthal movement break suddenly. It is fair to say that this is very unlikely to happen; more likely; only a few current blocks will move at a time. It is indeed recommended that the coil structure be sc modified that no domino effect can occur.

\section{iii. Longitudinal Extent of Stick-S1ip Process}

The highly uniform field creates highly uniform azimuthal forces along the whole length of the coil. Therefore, if conditions for slipping are reached at one point, the coil is ready to slip along the whole length, provided that windings and structures are also highly uniform. 


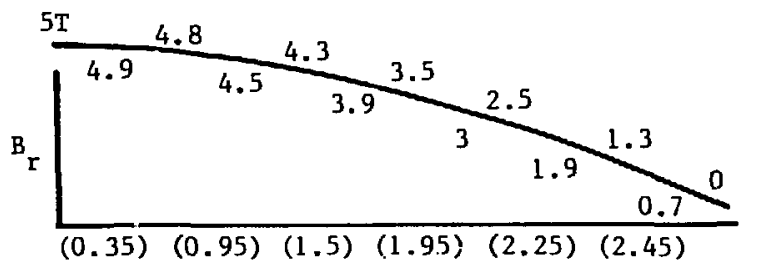

pole

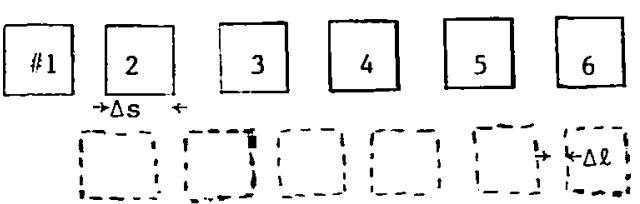

\begin{tabular}{|c|c|c|c|c|c|c|c|c|}
\hline N: & 5 & 11 & 15 & 18 & 21 & 22 & & number of turns in blocks \\
\hline I : & 19.9 & 43.7 & 59.6 & $7 \mathrm{I} .5$ & 8.3 .4 & 87.4 & $\mathrm{kA}$ & $\begin{array}{l}\text { total current in each } \\
\text { block, for } I=3.97 \mathrm{kA}\end{array}$ \\
\hline$F_{\theta}:$ & 97.5 & 196.6 & 232.4 & 214.5 & 158.5 & 61.8 & $\mathrm{kN} / \mathrm{m}$ & $\begin{array}{l}\text { azimuthal component of } \\
\text { Lorentz force per length of } \\
\text { current block }\end{array}$ \\
\hline $\mathbf{F}_{\mathbf{r}}:$ & 7 & 41.5 & 89.4 & 139.4 & 187.6 & 214.1 & $\mathrm{kN} /$ in & radial component \\
\hline$F_{\text {tot }}:$ & 97.75 & 200.9 & 249 & 255.8 & 245.6 & 222.8 & $\mathrm{kN} / \mathrm{m}$ & total Lorentz force \\
\hline$\Delta \mathrm{p}:$ & $\begin{array}{l}5.9 \\
0.85\end{array}$ & $\begin{array}{l}\text { I } 1.9 \\
1.72\end{array}$ & $\begin{array}{r}14.1 \\
2.0\end{array}$ & 13 & $\begin{array}{l}9.6 \\
1.4\end{array}$ & $\begin{array}{l}3.7 \\
0.5\end{array}$ & $\begin{array}{l}\text { MPa } \\
\text { kpsi }\end{array}$ & $\begin{array}{l}\text { azimuthal pressure differ- } \\
\text { ence across each block }\end{array}$ \\
\hline$\Sigma \Delta \mathrm{P}:$ & 5.9 & 17.8 & 31.9 & 44.9 & 54.5 & 58.2 & $\mathrm{MPa}$ & $\begin{array}{l}\text { accumulated pressure } \\
\text { (assuming the windings are } \\
\text { free to move in the } \\
\text { azinuthal direction) }\end{array}$ \\
\hline$\varepsilon:$ & 0.045 & 0.13 & 0.235 & 0.33 & 0.4 & 0.425 & $\%$ & $\begin{array}{l}\text { strain, assuming modulus of } \\
2 \text { Mpsi (13.6 GPa) }\end{array}$ \\
\hline$\Delta \ell:$ & 7 & 21 & 38 & 53 & 64 & 68 & $\mu m$ & compression of each block \\
\hline$\Delta \mathbf{s}=\Sigma \Delta \ell:$ & 251 & 244 & 223 & 185 & 132 & 68 & $\mu m$ & cumulative movement \\
\hline$F_{\theta} \times \Delta s:$ & 24.5 & 48 & 51.8 & 39.7 & 20.9 & 2.1 & $\mathrm{~J} / \mathrm{m}$ & $\begin{array}{l}\text { total energy released by } \\
\text { slip at full force } \\
\text { ( } 1 / 2 \text { stored elastically } \\
1 / 2 \text { dissipated in heat) }\end{array}$ \\
\hline
\end{tabular}

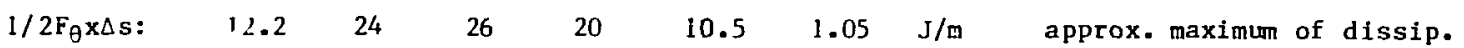

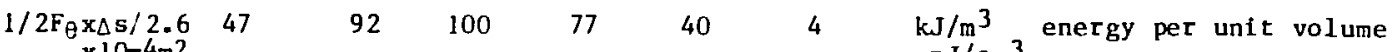
$\times 10-4 \mathrm{~m}^{2}=\mathrm{mJ} / \mathrm{cm}^{3}$

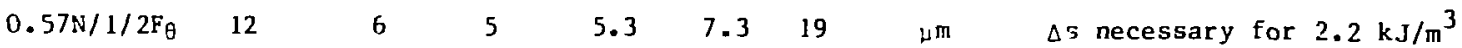

Radial component of magnetic field (assumed to vary like cos)

(average azimuthal field component)

the six current blocks

deformation under force

strain assuming modulus of compression of each block

(1/2 stored elastically total energy released by 
In reality the bond strength will vary along the length. A slip event wit.1 occur at a place of low bond strength. The slip event can propagate longitudinally by bending of the winding packet, and the bending strength of the winding will help to spread the excess forces caused by the broken bonds. Regions of higher bond strength will limit the longitudinal spread of the slip event. (See Figure N.)

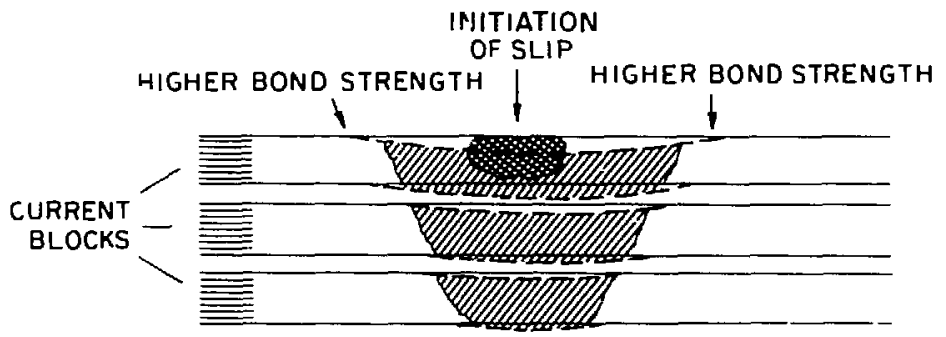

LONGITUDINAL EXTENT OF SLIP EVENT

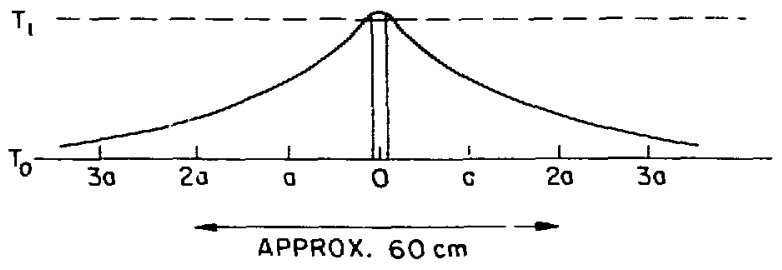

SKETCH OF MPZ TEMPERATURE DISTRIBUTION

Figure $\mathbb{N}$ Comparison of possible stick-slip event with the MPZ temperature distribution.

The longitudinal end regions of a slip event will be left in a state of enhanced stress; they are candidates for initiating locations of subsequent slip events.

The necessary data to calculate the longitudinal extent are generally not available; experimental measurement might be easier and more reliable than calculation. However, I doubt that accurate quantitative data are essential for the present argument. It is probably fair to guess that a slip event has a longitudinal extent of between $5 \mathrm{~cm}$ and $1 \mathrm{~m}$. It is important to recognize that the MPZ temperature distribution has a very similar longitudinal extent. Stickslip events are therefore very efficient in creating MPZ. An MPZ temperature distribution has an extent of approximately $4 \mathrm{xa}$, in this case about $60 \mathrm{~cm}$, and the total energy needed is 0.14 to $0.3 \mathrm{~J}$ or about 0.25 to $0.5 \mathrm{~J} / \mathrm{m}$. According to Tatle $\mathrm{I}$ this is less than $5 \%$ of the maximum available energy, i.e., a motion of only 10 to $15 \mu \mathrm{m}$ (or about 
half a mil). It seems therefore that once a stick-slip event taikes place more energy is available than needed to create the MPZ.

The final result of this discussion is then:

a) stick-slip events as described can indeed very easily lead to quenches.

b) current blocks 2 and 3 are most prone for quenching.

c) because of the longitudinal limitation of a slip event, a great many slip events are possible in a coil of 4.75 in. length; consequently a large number of training steps are encountered.

iv. Effect of Field Distribution

The curient blocks near the poles see a larger average magnetic field than those near the equator. Higher fields reduce $j_{0}$ and $T_{j}$ and therefore also reduce scability. Assuming the field to be $10 \%$ higher, consequently jo $10 \%$ lower, one expects a modification of Figure $J$ as indicated in Figure 0 . Solid lines indicate, as before, the size of the MPZ, i.e., the boundary between stable and unstable operatior. The dashed lines indicate the energy releases due to sticksiip. The energy releases are proportional to $j^{2}$, and the assumption is made that at $j / j_{o}=70 \%$ the equivalent of $0.4 \mathrm{~J}$ is released for a slip event in block 2. The other dashed curves indicate the relatively smaller energy of slip events for blocks $4,5,1$, and 6 , as obtained from Table I. Figure 0 shows then that block 2 is less stable than all the others.

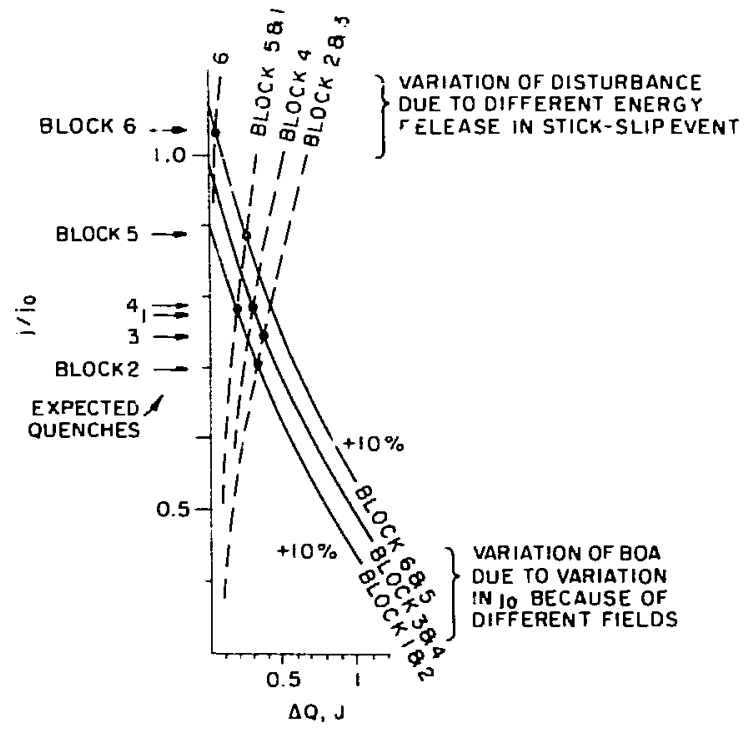

Figure 0 Differences in stability for different current blocks. 


\section{RECOMMENDATIONS AIMED AT IMPROVING ISABELLE DIPOLE PERFORMANCE}

i. What Information Might Be Useful

The foregoing discussion gives, I hope, a "feeling" for the stability of the ISABELLE dipoles. To describe the present situation better one needs more quantitative information. For accurate computer calculations of the BOA correct values for the various heat transport mechanisms should be available. Values for heat transfer to the helium gas and for heat conduction through the composite medium of winding and retaining structure are wanted. One alsn needs to know where quenches start; then the dominant disturbance mechanism may be established with some certainty. Accurate field calculations axe probably already available, thus Table I can be improved.

Throughout the discussion it was tacitly assumed that the experienced quenches are "MPZ-governed" and not "disturbance-governed". The former term means that there are many disturbances, generally occurring already below the quench current, and that the quench is initiated by disturbances that are just large enough to overcome the BOA. The latter term is appropriate when few large disturbances occur, much larger than required to overcome the BOA; the quench then will occur simply as a consequence of the disturbance and independently of the size of the MPZ. Training usually indicates MPZ-governed quenches and, with increasing quench number, progressively smaller disturbances, being fed from pockets of stored energy.

ii. Ways To Improve Stability

Most important and urgent, of course, is to improve stability to a point where the design field can bie reacked without quenches (i.e., with a rertain safety factor). There are two methods for tinis:

1. improve the $\mathrm{BOA}$,

2. reduce disturbances.

It is possible to pursue both methods with relatively minor changes in the ISABELLE dipole design.

1. Improving the BOA

The BOA (i.e., MPZ, $\triangle E$, extra heating) is improved by a) reducing the cuirent density, b) reducing the resistivity, c) improving heat transport out of tre windings.

a. Reduction of current density is easiest to achieve in blocks 1 to 3 because the available space now seems to be wasted. Instead of using passive filler, one might use a different braid, having higher $\mathrm{Cu}: \mathrm{SC}$ ratio. This remedy alone might suffice to reach the design field. It also would optimize the coil by equalizing the stability of all current blocks (see Figure 0 ). Overall reduction 
of current density could be achieved by reducing the i.d. of the windings. (This may necessitate relocation of correction coils.)

b. Reducing the resistance by changing the $\mathrm{Cu}: \mathrm{SC}$ ratio has been discussed and no stability improvement can be expected.

c. Heat transport could be improved by using aluminum as material for wedge spacers between c.urrent blocks. Increasing the coolant flow might also help (but I would not expect a big imp:ovement).

\section{Reduction of disturbances}

If indeed azimuthal stick-slip is the dominant disturbance, then a better anchoring of the current blocks is necessary. The nost obvious way is to use slightly enlarged wedge spacer pieces of metal as indicated in Figure $M$. No doubt, there are other nuethods to anchor the current blocks against azimuthal movement, but I would stay clear of epoxy bonding or similar sticking techniques. Subdivision of the current blocks ( 12 blocks instead of 6 only) may be necessary.

\section{CONCLUSIONS}

1. Very simple approximations indicate that disturbances with heat releases of the order of $0.1 \mathrm{~J}$ in the windings of the ISABELLE coils will cause quenches before reaching the design field of $5 T$.

2. The most likely mechanism for causing such disturbances is azimuthal stick-slip movement of the current blocks (this should be experimentally verified).

3. Movement of the order of $10^{-3} \mathrm{~cm}$ is sufficient to cause quenches.

4. The longitudinal extent of stick-slip movements is about the same as the longitudinal extent of the MP temperature distribution. This means that the disturbance is very efficient in creaing immedistely an MPZ temperature distribution.

5. Quenches in current block 2 are most likely. Blocks 5 and 6 are most stable.

6. Reducing the operating temperature from 4.5 to $3.8 \mathrm{~K}$ will shift the quench current upward by about $10 \%$.

7. Reducing the current density in block- 1 to 3 by use of the filling space for active conductor should easily increase the stability of these blocks to equal the stability of blocks 5 and 6 .

8. Using material with high thermal conductivity, such as $A 1$, as wedge spacers between current blocks will improve stability. 
9. Anchoring the current blocks against azimuthal movement will reduce the disturbances and therefore improve stability.

10. Suggested method for anchoring is to transfer azim thal forces via spacers between blocks to the inner and outer bands, as indicated in Figure $M$.

11. Further improvement in stability can be gained by reducing th: current density through allocating -ore spacc to the windings.

No:e: Recently I learned that the measured value for the normal resistivity of the braid is an order of magnitude higher than assumed here. See p. 4 where $z=18 \mathrm{u} \Omega \mathrm{cm}$ was estimated. Veasured values are 0.2 to $0.35 \mathrm{ir} \mathrm{cm}$. This brings the value of $\mathrm{j}^{2} 0$ to 200 to $400 \mathrm{~W} / \mathrm{cm}^{3}$ and makes stability that much worse. The volume of the resistive MPZ region becones one to two orders of magnitude smaller than calculated in Section IT. The limit of MPZ stability, $5_{j}=0.5$, lies between 25 and $30 \mathrm{~A}$ (see $\mathrm{p}$. 8). However, since the $: \mathbb{P Z}$ temperature distribution is iardly changed, the data and conclusions in the other sections are not affected. 